Article

\title{
Properties of Soy Protein Isolate Biopolymer Film Modified by Graphene
}

\author{
Yufei Han ${ }^{1,2,3}$, Kuang $\mathrm{Li}^{1,2,3}$ (1), Hui Chen ${ }^{1,2,3, *}$ and Jianzhang $\mathrm{Li}^{1,2,3, *}$ \\ 1 Key Laboratory of Wood Material Science and Utilization (Beijing Forestry University), \\ Ministry of Education, Beijing 100083, China; hanyufei@bjfu.edu.cn (Y.H.); kuangli@bjfu.edu.cn (K.L.) \\ 2 Beijing Key Laboratory of Wood Science and Engineering, Beijing Forestry University, Beijing 100083, China \\ 3 College of Materials Science and Technology, Beijing Forestry University, Beijing 100083, China \\ * Correspondence: chenhui@bjfu.edu.cn (H.C.); lijzh@bjfu.edu.cn (J.L.); Tel.: +86-10-6233-6912 (H.C.)
}

Received: 21 June 2017; Accepted: 25 July 2017; Published: 27 July 2017

\begin{abstract}
This study applied a facile and green approach to synthesize a stable graphene aqueous dispersion, and the graphene aqueous dispersion was employed to modify the renewable, compatible and biodegradable soy-protein-isolated (SPI) films to enhance their thermal stability, mechanical properties and water resistance. Atomic force microscopy (AFM) images confirmed the monolayer structure of graphene. The hydrogen bonds and $\pi-\pi$ interactions between graphene and the SPI molecules were showed with the attenuated total reflectance Fourier transform infrared (ATR FT-IR) spectroscopy, and X-ray diffraction (XRD). As expected, compared to the pure SPI film, the tensile strength (TS) of the film with $74 \%$ graphene increased by $27.22 \%$ and the total soluble matter (TSM) of the film with $93 \%$ graphene decreased by $11.30 \%$.
\end{abstract}

Keywords: soy protein isolate; graphene; mechanical property; water resistance

\section{Introduction}

Nowadays, with the increased awareness of sustainable development and environmental protection, interest has risen in developing biopolymer films as an environment friendly and renewable alternative to petroleum-based materials [1]. These films are mainly from natural polymers, such as protein, lipid biopolymer and cellulose, which offer the advantages of sustainability, biodegradability and biocompatibility [2].

Among the biopolymer studies, soy protein isolate (SPI), a common by-product of the edible oil industry, showed a wide range of potential applications in drug delivery, packaging and mulching fields due to its low cost, abundance, biocompatibility, sustainability and film-forming capacity [3-5]. However, the drawbacks of SPI films, such as poor mechanical strength and high water sensitivity have limited their applications [6,7]. Therefore, many efforts have been made to enhance their performance via physical methods, enzymatic treatments and chemical cross-linking approaches [8].

Recently, graphene has attracted increasing interest as an emerging functional material. Graphene is a two-dimensional (2D) crystalline monolayer sheet, with $\mathrm{sp}^{2}$-hybridized carbon atoms arranged in a honeycomb lattice [9-11]. The outstanding thermal, mechanical, electrical and hydrophobic properties offered broad applications in biomedicine, reinforced composites, catalytic, conductive materials, and energy resources $[9,10,12,13]$. The reported methods of synthesizing graphene were mainly exfoliation, epitaxial growth, and chemical vapor deposition (CVD) [14-16]. However, these methods have the disadvantages of toxicity, a lack of compatibility and the forming of additional defects. Therefore, a facile and green approach for preparing stable graphene aqueous dispersion was required.

Inspired by the excellent hydrophobic and mechanical properties of graphene, Wang et al., synthesized graphene-reinforced poly(vinyl alcohol) (PVA) composite films [17]. The results showed 
that the tensile strength increased by $212 \%$ and elongation increased by $34 \%$ with only $0.5 \mathrm{wt} \%$ graphene content. The water absorption ratio of graphene-PVA composite films decreased from 105.2 to $48.8 \%$. Jiang et al. explained that the enhanced performance was due to the hydrogen bonds between the PVA and the graphene molecules [18]. The graphene-nylon nanocomposites also exhibited obvious improvements in mechanical properties and water resistance with very low filler loading [19]. Zhang et al. fabricated ultra-strong, ultra-tough, and highly conductive rGO (reduced graphene oxide) films based on the hydrogel casting technique, demonstrating high performance through the synergistic effect from $\pi-\pi$ interactions and hydrogen bonds [20]. These previous studies indicated that graphene can achieve better enhancement effects due to the interactions between graphene and the polymer matrix.

In this study, we compounded series of graphene with different ultrasonic time via a facile method, and prepared renewable and environment friendly SPI-graphene composite films. The hydrogen bonds and $\pi-\pi$ interactions between the SPI and graphene molecules improved the mechanical properties, thermal stability and water resistance of the resultant composite films. This advanced performance provides SPI-graphene films wide potential application in drug delivery, packaging and the food industry.

\section{Materials and Methods}

\subsection{Materials}

SPI with a protein content of 95\% was purchased from Yuwang Ecological Food Industry Co., Ltd. (Yucheng, China). Graphite powder was provided by Sinopharm Chemical Reagent Co., Ltd. (Shanghai, China). Bovine serum albumin of biotechnology grade was obtained from Beijing Labest Bio Technology Co., Ltd. (Beijing, China). Glycerol (99\% purity) of biotechnology grade, sodium hydroxide of analytical grade and other chemical reactants of analytical grade were purchased from Beijing Chemical Reagents (Beijing, China).

\subsection{Synthesis of Aqueous Graphene Dispersion}

$50.0 \mathrm{mg}$ of bovine serum albumin (BSA) powder was mixed with $900 \mathrm{~mL}$ of deionized water at $50{ }^{\circ} \mathrm{C}$ and stirred for $12 \mathrm{~h}$. The $\mathrm{pH}$ of the aqueous BSA solution was adjusted to 3.6 with dilute $\mathrm{HCl}$ solution. Then $1 \mathrm{~g}$ graphite power were dispersed in $600 \mathrm{~mL}$ of the aqueous BSA solution. The mixture was probe-sonicated and stirred for $6,12,18,24,30$ and $36 \mathrm{~h}$. The product was allowed to stand for $24 \mathrm{~h}$ at room temperature to settle some of the unreacted graphite particles and large graphene aggregates. It was then centrifuged at $3000 \mathrm{rpm}$ for $30 \mathrm{~min}$ to separate the supernatant from the sediment. The concentration of aqueous graphene dispersion was calculated from the Beer-Lambert law with the extinction coefficient of graphene $\left(\alpha=1390 \mathrm{~mL} \cdot \mathrm{mg}^{-1} \cdot \mathrm{m}^{-1}\right)$ previously determined [21] at the wavelength of the highest absorbance peak $(269 \mathrm{~nm})$ in ultraviolet-visible absorption spectra.

\subsection{Prepare of Graphene-SPI Films}

The SPI film-forming solutions were prepared by SPI $(4.0 \mathrm{~g})$, glycerol $(2.0 \mathrm{~g})$, graphene aqueous dispersion and deionized water. The $\mathrm{pH}$ of the mixture was adjusted to $9.0 \pm 0.1$ with sodium hydroxide solution, then heated in a water bath at $85^{\circ} \mathrm{C}$ for $30 \mathrm{~min}$. The solution $(75.0 \mathrm{~g})$ was poured onto a Teflon-coated plate after removing bubbles by ultrasound treatment. The films were dried in drying oven at $45^{\circ} \mathrm{C}$ for $24 \mathrm{~h}$, and preconditioned at the relative humidity of $50 \pm 2 \%$ and temperature of $25 \pm 2{ }^{\circ} \mathrm{C}$ for $48 \mathrm{~h}$ before testing. The composition parts of the films were presented in Table 1 . The graphene content was calculated by the proportion of graphene aqueous dispersion in the entire solution system, and applied to the whole experiment. 
Table 1. The composition parts of graphene-SPI films.

\begin{tabular}{cccccc}
\hline Sample & SPI (g) & Glycerol $(\mathrm{g})$ & Water $(\mathrm{g})$ & Graphene Aqueous Dispersion $(\mathbf{m L})$ & Graphene Content $(\%)$ \\
\hline A & 4.0 & 2.0 & 0 & 75.0 & 93.0 \\
B & 4.0 & 2.0 & 15.0 & 60.0 & 74.0 \\
C & 4.0 & 2.0 & 30.0 & 45.0 & 56.0 \\
D & 4.0 & 2.0 & 45.0 & 30.0 & 37.0 \\
E & 4.0 & 2.0 & 60.0 & 15.0 & 19.0 \\
F & 4.0 & 2.0 & 75.0 & 0 & 0 \\
\hline
\end{tabular}

\subsection{Characterization of Graphene Aqueous Dispersion and SPI-Graphene Films}

The TU-1901 ultraviolet-visible spectrophotometer (UV-vis, Beijing Purkinje General, Beijing, China) was used to record the absorption spectra of aqueous graphene within the range of $250-400 \mathrm{~nm}$.

The morphology of graphene was observed by atomic force microscopy (AFM, Bruker Multimode 8, Billerica, MA, USA). The topographic (height) and phase images were collected in the tapping mode using a monolithic Si tip with a resonance frequency between 250 and $300 \mathrm{kHz}$.

The surface morphology of the graphene-SPI films was observed using the SU8010 field emission scanning electron microscopy (SEM, Hitachi Ltd., Tokyo, Japan) with an acceleration voltage of $5 \mathrm{kV}$.

The chemical structure of the graphene-SPI films was examined according to the Nicolet 6700 attenuated total reflectance Fourier transform infrared spectroscopy (ATR FT-IR, Thermo Scientific, Pittsburgh, PA, USA) with a wave number range from 650 to $4000 \mathrm{~cm}^{-1}$. A total of 32 scans were performed at $4 \mathrm{~cm}^{-1}$ resolution.

Samples were dried at $45^{\circ} \mathrm{C}$ for $24 \mathrm{~h}$ before testing. The thermal stability of the graphene-SPI films was measured using the Q50 thermo gravimetric analysis (TGA) analyzer (TA Instrument, New Castle, DE, USA) with a rate of $10{ }^{\circ} \mathrm{C} \cdot \mathrm{min}^{-1}$. The temperature ranged from 30 to $600{ }^{\circ} \mathrm{C}$ under a nitrogen atmosphere $\left(100 \mathrm{~mL} \cdot \mathrm{min}^{-1}\right)$ to avoid thermo-oxidative reactions.

X-ray diffraction $(\mathrm{XRD})$ patterns were observed by the D8 advance diffractometer (Bruker, Billerica, MA, USA) equipped with a $\mathrm{Cu} \mathrm{K} \alpha$ radiation source. The $2 \theta$ value was ranged from $5^{\circ}$ to $60^{\circ}$ in continuous scanning mode with an increment of $0.02^{\circ}$.

The surface hydrophilicity of the graphene-SPI films was investigated using the water contact angles (WCA, OCA-20 Dataphysics Instruments GmbH, Filderstadt, Germany). A sessile droplet ( $3 \mu \mathrm{L}$, measured by microsyringe) of distilled water was dropped onto the surface of the films. The angles of both sides were recorded at an interval from 0.1 to $180 \mathrm{~s}$. Five replicates were conducted for each specimen.

\subsection{Mechanical Properties}

Each sample was cut into $10 \times 80 \mathrm{~mm}$ pieces and the thickness of the film was measured with a digital micrometer $(0-25 \pm 0.001 \mathrm{~mm})$ before testing. The mechanical properties were determined on the tensile testing machine (WDW3020, Changchun Kexin Instrument Co., Ltd., Changchun, China) according to ISO527-3:1995 (E). The tensile strength (TS), elongation at break (EB) and Young's modulus $(E)$ were determined by five replicates of each film.

\subsection{Water Barrier Properties}

Three specimens $\left(20 \times 20 \mathrm{~mm}^{2}\right)$ of each film were tested to determine the moisture content $(M C)$, total solution matter (TSM) and water uptake (WU).

The initial mass $\left(m_{\mathrm{a}}\right)$ was determined. The specimens were dried in an air-circulating oven at $103 \pm 2{ }^{\circ} \mathrm{C}$ for $24 \mathrm{~h}$ and weighed again $\left(m_{\mathrm{b}}\right) . M C$ was calculated as follows:

$$
\operatorname{MC}(\%)=\left(m_{\mathrm{a}}-m_{\mathrm{b}}\right) / m_{\mathrm{a}} \times 100
$$

Afterward, specimens were immersed in a breaker containing $30 \mathrm{~mL}$ of deionized water for $24 \mathrm{~h}$ at room temperature. Sodium azide was also added to the breaker to inhibit microbial growth. 
The insoluble matter was separated and dried in an air-circulating oven at $103 \pm 2{ }^{\circ} \mathrm{C}$ for $24 \mathrm{~h}$ again. The mass of the specimens was marked as $m_{\mathrm{c}}$. TSM was calculated as follows:

$$
\operatorname{TSM}(\%)=\left(m_{\mathrm{b}}-m_{\mathrm{c}}\right) / m_{\mathrm{b}} \times 100
$$

The specimens were firstly stored in $\mathrm{P}_{2} \mathrm{O}_{5}$-regulated desiccators ( $0 \%$ relative humidity) for $48 \mathrm{~h}$, and the initial mass was weighed as $m_{\mathrm{d}}$. The films were immersed in a breaker with $30 \mathrm{~mL}$ of deionized water at room temperature for $24 \mathrm{~h}$. Then the water was moved and the mass of specimens were weighted as $m_{\mathrm{e}}$. WU was calculated as follows:

$$
W U(\%)=\left(m_{\mathrm{e}}-m_{\mathrm{d}}\right) / m_{\mathrm{d}} \times 100
$$

\section{Results}

\subsection{Characterization of Graphene Aqueous Dispersion}

UV-vis spectroscopy was used to confirm the presence of graphene. Figure 1 shows the UV-vis absorption spectra of graphene with different ultrasonic times of 6, 12, 18, 24, 30 and $36 \mathrm{~h}$. The shapes of different spectra were similar, except the ultrasonic time of $30 \mathrm{~h}$, which may due to the excessive ultraviolet terminal absorption. Graphene has a broad absorption spectrum of $269 \mathrm{~nm}^{-1}[22,23]$. The highest absorbance peak appeared when the ultrasonic time was $24 \mathrm{~h}$ and the graphene concentration was $0.049 \mathrm{mg} / \mathrm{mL}$ calculated by the Beer-Lambert law. An obvious blue shift occurred with the increase of the ultrasonic time. It demonstrated that the graphene was prepared successfully.

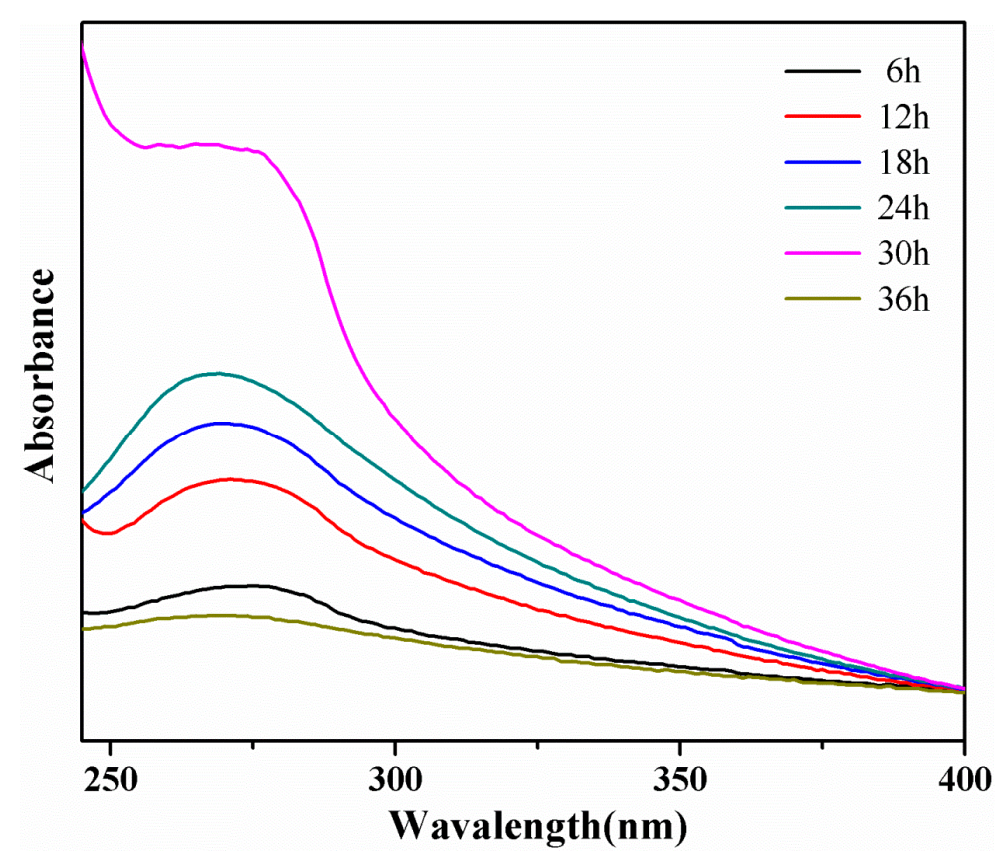

Figure 1. UV-vis absorption spectra of graphene with ultrasonic time.

The stripped graphene aqueous dispersion $(1 \mathrm{~mL})$ was obtained, then diluted five times directly before investigated the surface morphology of the graphene by AFM. The 2D morphologies and height images are shown in Figure 2. It was obvious that the 2D morphologies exhibitd the shape of monolayer in Figure 2a,c [24], and the white spherical structure was BSA. The height images indicated that the thickness of the graphene layer was about $1 \mathrm{~nm}$ in Figure $2 b, \mathrm{~d}$. These results demonstrated that the graphene was prepared successfully, which was consistent with the results of the UV-vis. 

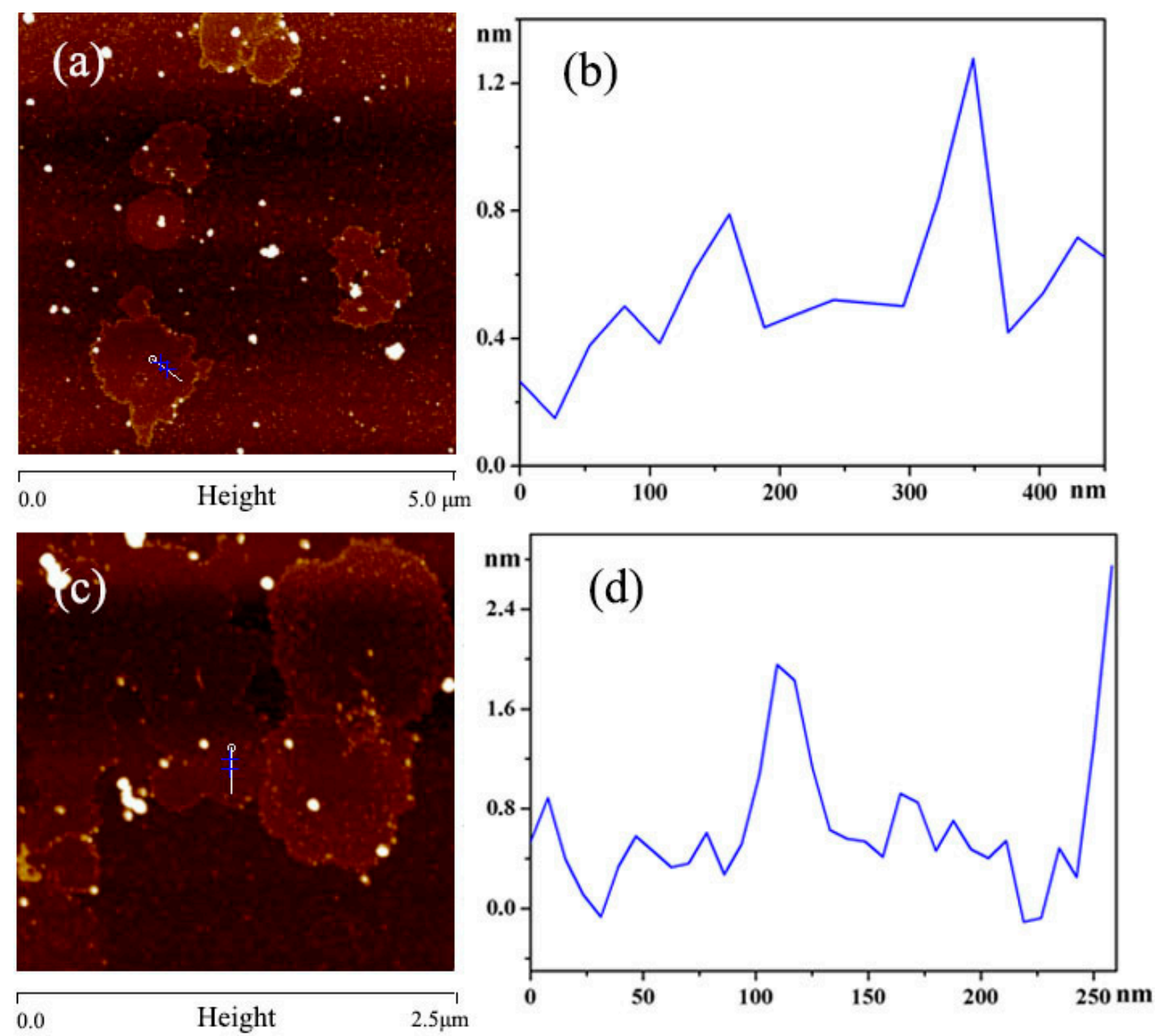

Figure 2. AFM images of graphene: (a,c) 2D morphologies of graphene with different magnifications; $(\mathbf{b}, \mathbf{d})$ height images of graphene with different magnifications.

\subsection{Structural Analysis of SPI-Based Films}

ATR FT-IR was used to investigate the structural characteristics of the SPI-based films (Figure 3). These spectra showed similar absorption peaks in the range of 4000 to $600 \mathrm{~cm}^{-1}$. The increasing intensity of the broad absorption band at $3274 \mathrm{~cm}^{-1}$ was attributed to the $\mathrm{O}-\mathrm{H}$ stretching in the SPI films [6]. The peaks at $2930 \mathrm{~cm}^{-1}$ were the stretching vibrations of the methylene groups [25]. Among all the SPI-based films, the peaks at $1628,1538,1235 \mathrm{~cm}^{-1}$ were the main characteristic amide bonds of amide I ( $\mathrm{C}=\mathrm{O}$ stretching), amide II ( $\mathrm{N}-\mathrm{H}$ bending), and amide III ( $\mathrm{C}-\mathrm{N}$ and $\mathrm{N}-\mathrm{H}$ stretching), respectively [26,27]. The band at $1038 \mathrm{~cm}^{-1}$ corresponded to the hydrogen bond between SPI and the graphene molecules. Based on the above analysis, we concluded that the interactions between SPI and the graphene molecules were mainly due to the hydrogen bonds, and the $\pi-\pi$ interactions also provided a possibility for the modification of SPI molecules.

The structure of SPI-based films was observed by XRD (Figure 4). Clearly, the XRD patterns of these SPI-based films were similar. The two wide diffraction peaks at $2 \theta=9.1^{\circ}$ and $20^{\circ}$ belonged to the SPI secondary conformation- $\alpha$-helix and $\beta$-sheet, respectively. Furthermore, the intensity of the peaks at $2 \theta=9.1^{\circ}$ and $20^{\circ}$ were decreased due to the increased amount of graphene [11]. The result indicated that the addition of graphene transformed the conformation of the soy protein molecules and destroyed the regular arrangement of the SPI molecular chains. The diffraction peak at $2 \theta=26.4^{\circ}$ corresponded to graphene, which showed good compatibility between graphene and the SPI matrix. 


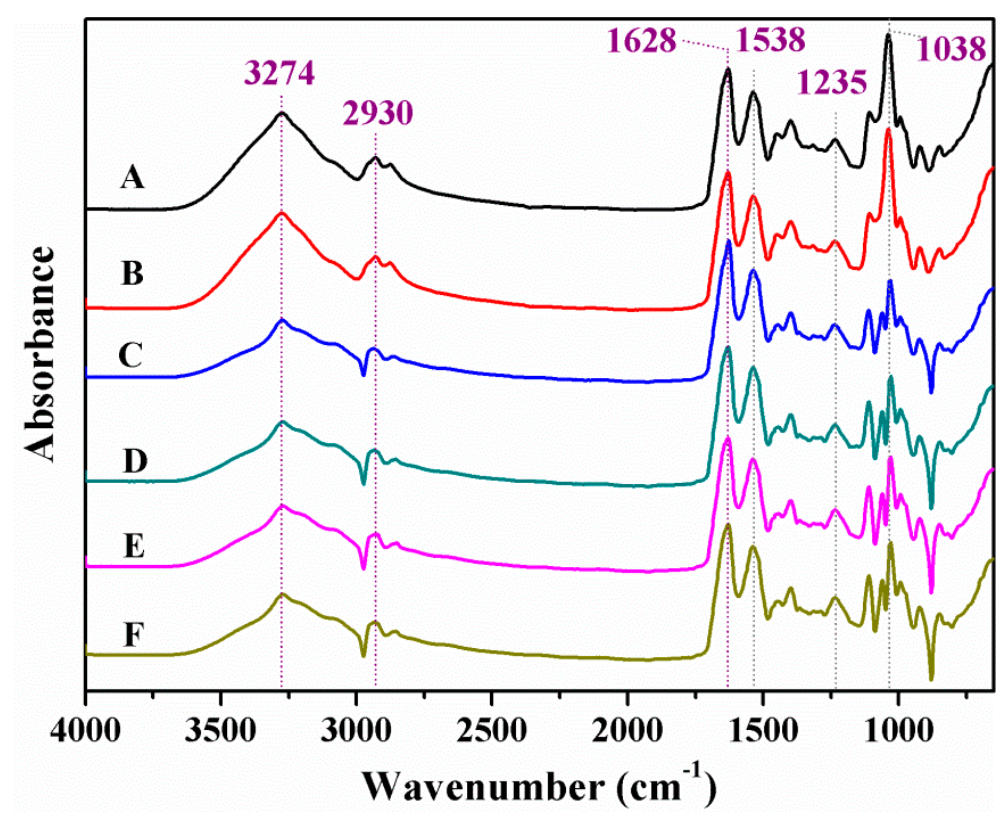

Figure 3. ATR FT-IR spectra of different SPI-based films.

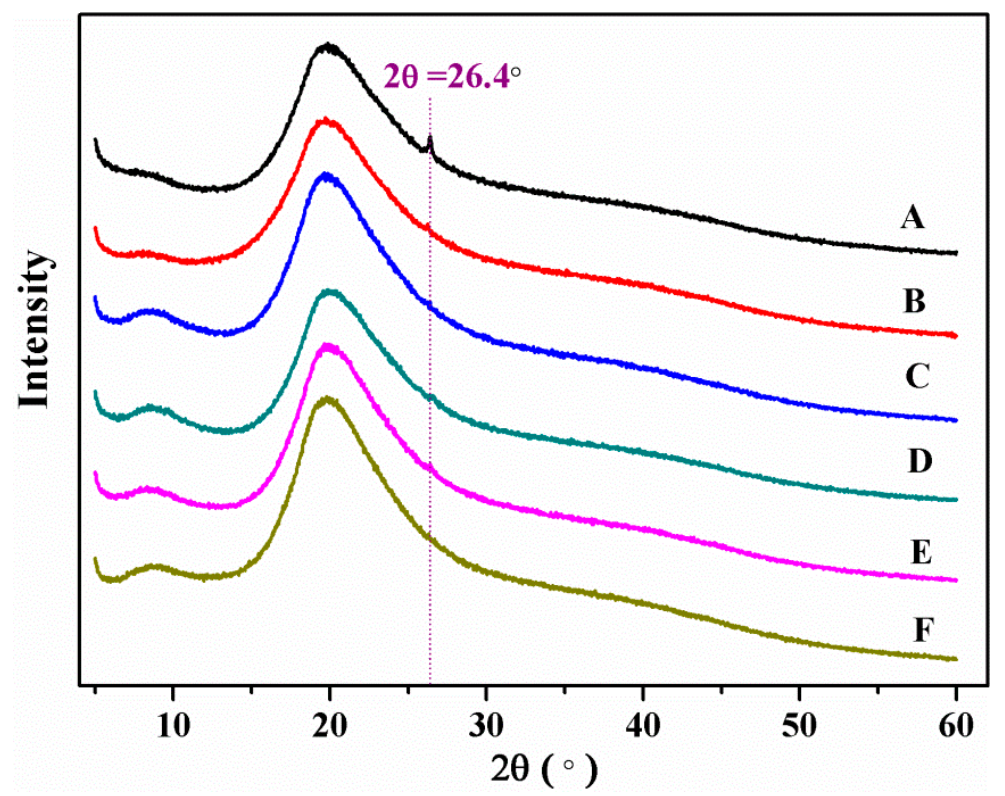

Figure 4. XRD patterns of different SPI-based films.

\subsection{Micromorphology of SPI-Based Films}

The surface morphology of graphene-SPI films was observed by SEM (Figure 5). Obviously, Figure 5a-d shows the surface morphology with straight line-like shapes on the modified SPI-based films, compared with the smoother surface of the pure SPI film in Figure $5 f$ [28]. The results indicated that graphene was completely compatible with the SPI matrix, and that the introduction of the graphene changed the crystal structures of the SPI molecules and increased the regularity of the molecules' arrangement. 

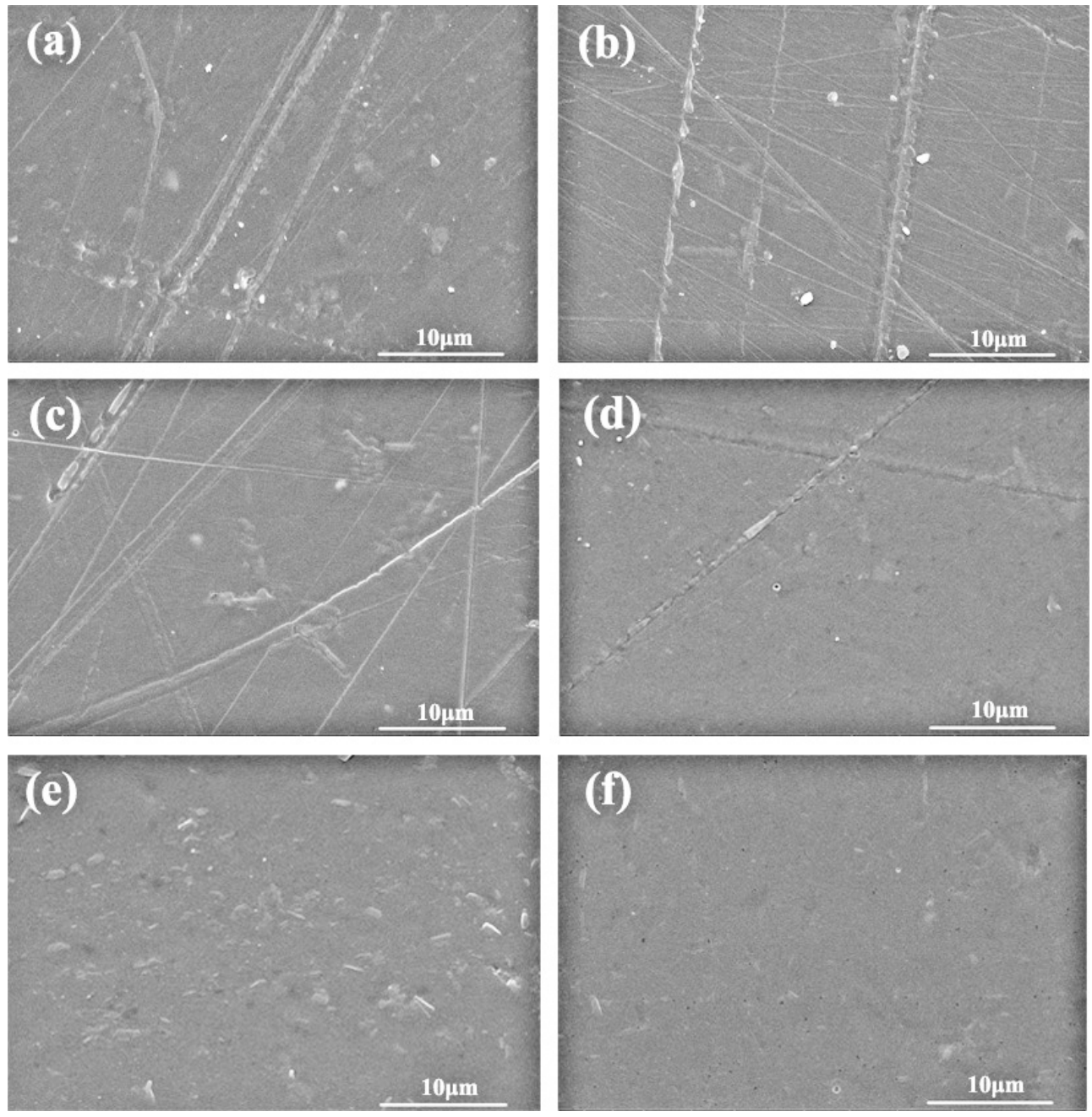

Figure 5. SEM images of SPI-based films: (a) 93\% graphene aqueous dispersion; (b) 74\% graphene aqueous dispersion; (c) 56\% graphene aqueous dispersion; (d) 37\% graphene aqueous dispersion; (e) $19 \%$ graphene aqueous dispersion; (f) the pure SPI film.

\subsection{Thermal Stability of SPI-Based Films}

The thermal properties of these SPI-based films were investigated by thermos-gravimetric (TG) and derivative TG (DTG) analysis, as shown in Figure 6. The thermal degradation data were summarized in Table 2. The initial degradation stage from 40 to $100{ }^{\circ} \mathrm{C}$ was the dehydration reaction. The second stage from 100 to $250^{\circ} \mathrm{C}$ was the degradation of glycerol. The last stage from 250 to $400{ }^{\circ} \mathrm{C}$ was mainly related to the breaking of the hydrogen bond and the degradation of backbone peptides [29-31]. The addition of graphene improved the maximum degradation temperature. Compared to the pure SPI film $(\mathrm{F})$, the temperature at the maximal degradation rate $\left(T_{\max 1,2}\right)$ of sample B (with $74 \%$ graphene content) increased from 151 to $195^{\circ} \mathrm{C}$, and from 293 to $309^{\circ} \mathrm{C}$. Overall, the improved thermal stability was attributed to the hydrogen bonds and $\pi-\pi$ interactions between graphene and the SPI matrix. However, the excessive content of graphene may have strengthened the $\pi-\pi$ interactions between graphene molecules, thereby weakening the interactions between the graphene and the SPI molecules. 

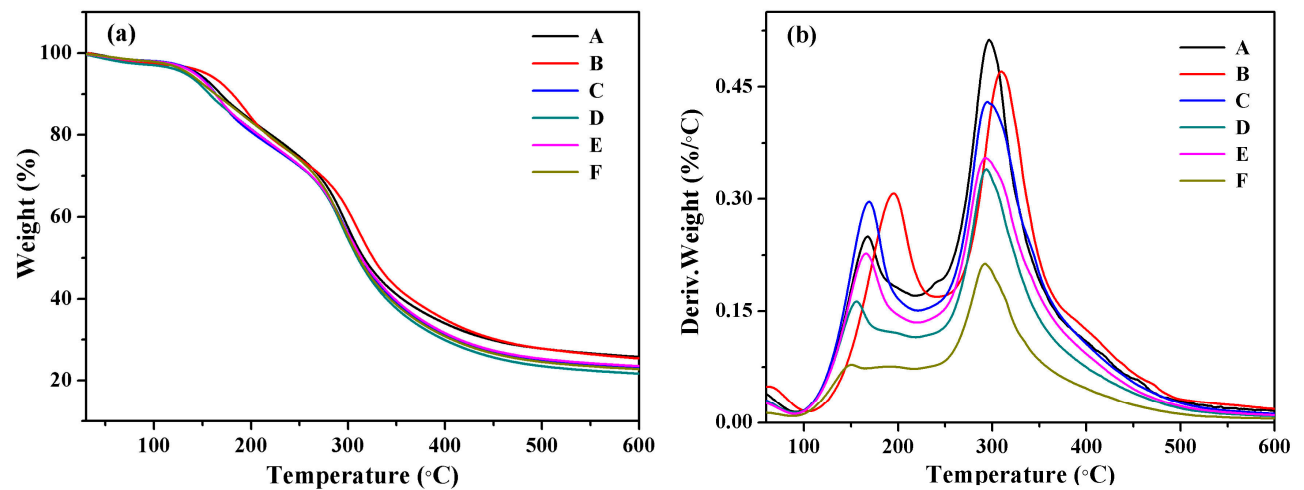

Figure 6. (a) The thermo gravimetric (TG) and (b) derivative TG (DTG) curves of SPI-based films.

Table 2. TG parameters for the thermal degradation of SPI-based films.

\begin{tabular}{ccc}
\hline Sample & $\boldsymbol{T}_{\boldsymbol{m a x} \mathbf{1}}{ }^{\mathbf{a}}\left({ }^{\circ} \mathbf{C}\right)$ & $\boldsymbol{T}_{\boldsymbol{m a x} \mathbf{2}}{ }^{\mathbf{a}}\left({ }^{\circ} \mathbf{C}\right)$ \\
\hline A & 167 & 297 \\
B & 195 & 309 \\
C & 169 & 298 \\
D & 156 & 294 \\
E & 166 & 292 \\
F & 151 & 293 \\
\hline \multicolumn{3}{c}{}
\end{tabular}

\subsection{Mechanical Properties and Water Resistance}

The results of tensile strength (TS), Young's modulus $(E)$ and elongation at break $(E B)$ of SPI-based films are shown in Figure 7 and Table 3. The stress-strain curves in Figure 7 show that the SPI-based films experienced stretching deformation and fracture failure after the application of a certain amount of load. The addition of graphene improved the $T S$ and $E$, while reducing the $E B$. Compared to the pure SPI film, the TS of sample B (with 74\% graphene content) increased from 4.74 to $6.03 \mathrm{Mpa}$, accounting for the increase of $27.22 \%$. The results may be attributed to the deformation of SPI molecule chains. Graphene was distributed in the SPI matrix in the form of a single layer, which enhanced interaction and prevented slipping [32-34]. However, the excessive introduction of graphene may have strengthened the $\pi-\pi$ interactions between graphene molecules, thereby weakening the interaction between the graphene and the SPI molecules.

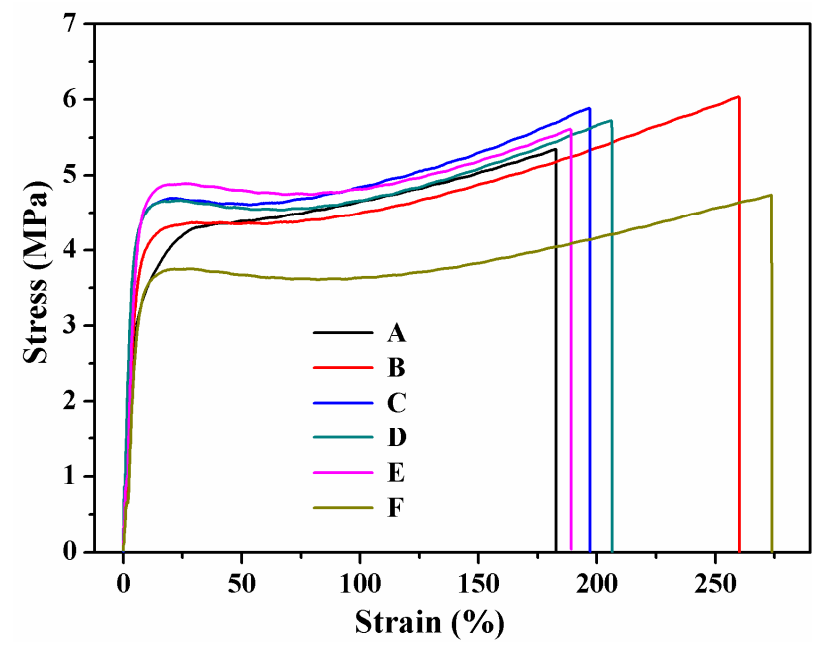

Figure 7. Stress-strain curves of different SPI-based films. 
Table 3. The thickness, tensile strength (TS), Young's modulus (E) and elongation at break (EB) of different SPI-based films.

\begin{tabular}{ccccc}
\hline Sample & Thickness (mm) & TS (MPa) & $\boldsymbol{E}$ (MPa) & $\boldsymbol{E B}(\mathbf{\%})$ \\
\hline A & $0.32(0.028)^{\text {a }}$ & $5.35(0.08)$ & $71.29(6.97)$ & $182.84(4.58)$ \\
B & $0.32(0.025)$ & $6.03(0.29)$ & $113.03(0.26)$ & $260.13(6.69)$ \\
C & $0.29(0.010)$ & $5.88(0.17)$ & $104.99(5.91)$ & $197.07(2.54)$ \\
D & $0.31(0.011)$ & $5.63(0.37)$ & $89.84(2.53)$ & $206.01(4.83)$ \\
E & $0.29(0.015)$ & $5.60(0.25)$ & $58.34(4.25)$ & $189.09(4.58)$ \\
F & $0.29(0.035)$ & $4.74(0.18)$ & $47.58(4.45)$ & $273.91(1.84)$ \\
\hline \multicolumn{6}{c}{ a Mean (standard deviation). }
\end{tabular}

${ }^{a}$ Mean (standard deviation).

The water contact angles of SPI-based films are shown in Figure 8, indicating the surface hydrophobia of the SPI-based films. As can be seen, compared to the pure SPI film (F), the contact angle of the modified SPI films increased obviously, which may be interpreted as the interaction between graphene and the SPI molecules exposed more hydrophobic groups, thereby exhibiting improved surface hydrophobic properties $[4,35]$.

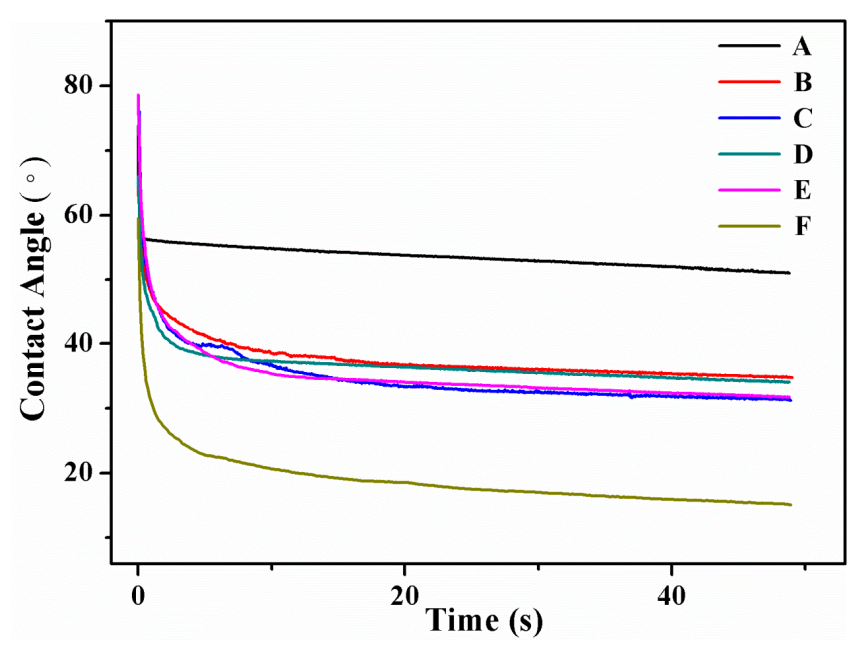

Figure 8. Water contact angle of different SPI-based films.

Table 4 showed the moisture content (MC), total soluble matter (TSM) and water uptake (WU) of the six groups of SPI-based film samples. The introduction of graphene did not result in significant changes in the $M C$ result. The addition of graphene decreased the TSM and WU, but the WU trend was not obvious. Compared to the pure SPI film, the TSM of sample A (with 93\% graphene content) decreased by $11.30 \%$. The results may be accounted as the outstanding compatibility and strong interactions between graphene and the SPI matrix, which exposed more hydrophobic groups, thereby exhibiting improved surface hydrophobic properties [36-38].

Table 4. The moisture content (MC), total soluble matter (TSM) and water uptake of different SPI-based films.

\begin{tabular}{cccc}
\hline Sample & \multicolumn{1}{c}{$\boldsymbol{M C}(\mathbf{\%})$} & TSM (\%) & WU (\%) \\
\hline A & $20.84(0.14)^{\text {a }}$ & $29.60(0.09)$ & $190.74(4.40)$ \\
B & $21.98(0.15)$ & $30.14(0.25)$ & $216.29(2.22)$ \\
C & $19.75(0.48)$ & $31.84(0.18)$ & $194.14(4.81)$ \\
D & $19.90(0.40)$ & $31.95(0.17)$ & $221.64(1.22)$ \\
E & $20.70(0.03)$ & $31.40(0.52)$ & $201.97(5.93)$ \\
F & $20.18(0.02)$ & $33.37(0.86)$ & $261.79(2.71)$ \\
\hline \multicolumn{5}{c}{ a Mean (standard deviation). }
\end{tabular}




\section{Conclusions}

In the study, we synthesized graphene aqueous dispersion via a simple and green method successfully. Composite SPI-graphene films with enhanced thermal stability, mechanical properties and water resistance were prepared. When preparing the graphene aqueous dispersion, the best ultrasonic time was $24 \mathrm{~h}$. Compared to the pure SPI film, the TS of sample B (with $74 \%$ graphene content) increased by $27.22 \%$. Water resistance and thermal abilities were also improved due to the addition of graphene. This improved performance may be due to the hydrogen bonds and $\pi-\pi$ interactions between graphene and the SPI matrix, which were confirmed by the ATR FT-IR and XRD. Overall, this research indicated that SPI-graphene composite films have potential applications in drug delivery, packaging and mulching.

Acknowledgments: The authors are grateful for financial support from the Fundamental Research Funds for the Central Universities (BLX201601), the Beijing Natural Science Foundation (2151003) and the Special Fund for Forestry Research in the Public Interest (Project 201404501).

Author Contributions: Yufei Han and Hui Chen conceived and designed the experiments; Yufei Han and Kuang Li performed the experiments and analyzed the data; Yufei Han wrote the main manuscript text; Hui Chen and Jianzhang Li supervised and directed the project; all authors reviewed the manuscript.

Conflicts of Interest: The authors declare no conflict of interest.

\section{References}

1. Koshy, R.R.; Mary, S.K.; Thomas, S.; Pothan, L.A. Environment friendly green composites based on soy protein isolate-A review. Food Hydrocoll. 2015, 50, 174-192. [CrossRef]

2. Ciannamea, E.M.; Stefani, P.M.; Ruseckaite, R.A. Physical and mechanical properties of compression molded and solution casting soybean protein concentrate based films. Food Hydrocoll. 2014, 38, 193-204. [CrossRef]

3. Tansaz, S.; Boccaccini, A.R. Biomedical applications of soy protein: A brief overview. J. Biomed. Mater. Res. A 2016, 104, 553-569. [CrossRef] [PubMed]

4. Galus, S.; Mathieu, H.; Lenart, A.; Debeaufort, F. Effect of modified starch or maltodextrin incorporation on the barrier and mechanical properties, moisture sensitivity and appearance of soy protein isolate-based edible films. Innov. Food Sci. Emerg. Technol. 2012, 16, 148-154. [CrossRef]

5. Dash, S.; Swain, S.K. Effect of nanoboron nitride on the physical and chemical properties of soy protein. Compos. Sci. Technol. 2013, 84, 39-43. [CrossRef]

6. González, A.; Strumia, M.C.; Alvarez Igarzabal, C.I. Cross-linked soy protein as material for biodegradable films: Synthesis, characterization and biodegradation. J. Food Eng. 2011, 106, 331-338.

7. Song, X.; Zhou, C.; Fu, F.; Chen, Z.; Wu, Q. Effect of high-pressure homogenization on particle size and film properties of soy protein isolate. Ind. Crops Prod. 2013, 43, 538-544. [CrossRef]

8. Xing, F.; Zhang, S.; Li, J.; Li, L.; Shi, J. Crosslinked chitosan-based biocomposite films modified with soy protein isolate. Polym. Compos. 2016. [CrossRef]

9. Rao, C.N.R.; Sood, A.K.; Subrahmanyam, K.S.; Govindaraj, A. Graphene: The new two-dimensional nanomaterial. Angew. Chem. Int. Ed. 2009, 48, 7752-7777. [CrossRef] [PubMed]

10. Kuilla, T.; Bhadra, S.; Yao, D.H.; Kim, N.H.; Bose, S.; Lee, J.H. Recent advances in graphene based polymer composites. Prog. Polym. Sci. 2010, 35, 1350-1375. [CrossRef]

11. Sun, H.; Ge, G.; Zhu, J.; Yan, H.; Lu, Y.; Wu, Y.; Wan, J.; Han, M.; Luo, Y. High electrical conductivity of graphene-based transparent conductive films with silver nanocomposites. RSC Adv. 2015, 5, 108044-108049. [CrossRef]

12. Stankovich, S.; Dikin, D.A.; Dommett, G.H.B.; Kohlhaas, K.M.; Zimney, E.J.; Stach, E.A.; Piner, R.D.; Nguyen, S.T.; Ruoff, R.S. Graphene-based composite materials. Nature 2006, 442, 282-286. [CrossRef] [PubMed]

13. Lee, C.; Wei, X.D.; Kysar, J.W.; Hone, J. Measurement of the elastic properties and intrinsic strength of monolayer graphene. Science 2008, 321, 385-388. [CrossRef] [PubMed]

14. Whitener, K.E.; Sheehan, P.E. Graphene synthesis. Diam. Relat. Mater. 2014, 46, 25-34. [CrossRef]

15. Shams, S.S.; Zhang, R.; Zhu, J. Graphene synthesis: A review. Mater. Sci. Pol. 2015, 33, 566-578. [CrossRef]

16. Gurunathan, S.; Han, J.; Kim, J.H. Humanin: A novel functional molecule for the green synthesis of graphene. Colloids Surf. B Biointerfaces 2013, 111, 376-383. [CrossRef] [PubMed] 
17. Wang, J.; Wang, X.; Xu, C.; Zhang, M.; Shang, X. Preparation of graphene/poly(vinyl alcohol) nanocomposites with enhanced mechanical properties and water resistance. Polym. Int. 2011, 60, 816-822. [CrossRef]

18. Zhang, Y.; Gong, S.; Zhang, Q.; Ming, P.; Wan, S.; Peng, J.; Jiang, L.; Cheng, Q. Graphene-based artificial nacre nanocomposites. Chem. Soc. Rev. 2016, 45, 2378-2395. [CrossRef] [PubMed]

19. Jin, J.; Rafiq, R.; Gill, Y.Q.; Song, M. Preparation and characterization of high performance of graphene/nylon nanocomposites. Eur. Polym. J. 2013, 49, 2617-2626. [CrossRef]

20. Zhang, M.; Huang, L.; Chen, J.; Li, C.; Shi, G. Ultratough, ultrastrong, and highly conductive graphene films with arbitrary sizes. Adv. Mater. 2014, 26, 7588-7592. [CrossRef] [PubMed]

21. Guardia, L.; Fernández-Merino, M.J.; Paredes, J.I.; Solís-Fernández, P.; Villar-Rodil, S.; Martínez-Alonso, A.; Tascón, J.M.D. High-throughput production of pristine graphene in an aqueous dispersion assisted by non-ionic surfactants. Carbon 2011, 49, 1653-1662. [CrossRef]

22. Huang, L.Y.; Lu, C.X.; Wang, F.; Dong, X.Z. Piezoelectric property of pvdf/graphene composite films using $1 \mathrm{H}, 1 \mathrm{H}, 2 \mathrm{H}, 2 \mathrm{H}$-perfluorooctyltriethoxysilane as a modifying agent. J. Alloys Compd. 2016, 688, 885-892. [CrossRef]

23. Hajian, M.; Reisi, M.R.; Koohmareh, G.A.; Zanjani Jam, A.R. Preparation and characterization of polyvinylbutyral/graphene nanocomposite. J. Polym. Res. 2012, 19, 9966. [CrossRef]

24. Mishchenko, A.; Eckmann, A.; Grigorieva, I.V.; Novoselov, K.S. Fluorination Clusters on Graphene Resolved by Conductive AFM; Springer: Berlin, Germany, 2016; pp. 19-24.

25. Pan, H.; Jiang, B.; Chen, J.; Jin, Z. Blend-modification of soy protein/lauric acid edible films using polysaccharides. Food Chem. 2014, 151,1-6. [CrossRef] [PubMed]

26. González, A.; Alvarez Igarzabal, C.I. Soy protein-Poly (lactic acid) bilayer films as biodegradable material for active food packaging. Food Hydrocoll. 2013, 33, 289-296.

27. Mauri, A.N.; Añón, M.C. Effect of solution ph on solubility and some structural properties of soybean protein isolate films. J. Sci. Food Agric. 2006, 86, 1064-1072. [CrossRef]

28. Ahn, H.S.; Kim, H.; Kim, J.M.; Park, S.C.; Kim, J.M.; Kim, J.; Kim, M.H. Controllable pore size of three dimensional self-assembled foam-like graphene and its wettability. Carbon 2013, 64, 27-34. [CrossRef]

29. Kumar, R.; Anandjiwala, R.D.; Kumar, A. Thermal and mechanical properties of mandelic acid-incorporated soy protein films. J. Ther. Anal. Calorim. 2015, 123, 1273-1279. [CrossRef]

30. González, A.; Alvarez Igarzabal, C.I. Nanocrystal-reinforced soy protein films and their application as active packaging. Food Hydrocoll. 2015, 43, 777-784. [CrossRef]

31. Swain, S.K.; Priyadarshini, P.P.; Patra, S.K. Soy protein/clay bionanocomposites as ideal packaging materials. Polym. Plast. Technol. Eng. 2012, 51, 1282-1287. [CrossRef]

32. Kang, H.; Wang, Z.; Zhang, W.; Li, J.; Zhang, S. Physico-chemical properties improvement of soy protein isolate films through caffeic acid incorporation and tri-functional aziridine hybridization. Food Hydrocoll. 2016, 61, 923-932. [CrossRef]

33. Tian, H.; Xu, G.; Yang, B.; Guo, G. Microstructure and mechanical properties of soy protein/agar blend films: Effect of composition and processing methods. J. Food Eng. 2011, 107, 21-26. [CrossRef]

34. Wang, X.; Hu, L.; Li, C.; Gan, L.; He, M.; He, X.; Tian, W.; Li, M.; Xu, L.; Li, Y.; et al. Improvement in physical and biological properties of chitosan/soy protein films by surface grafted heparin. Int. J. Biol. Macromol. 2016, 83, 19-29. [CrossRef] [PubMed]

35. Li, K.; Chen, H.; Li, Y.; Li, J.; He, J. Endogenous cu and zn nanocluster-regulated soy protein isolate films: Excellent hydrophobicity and flexibility. RSC Adv. 2015, 5, 66543-66548. [CrossRef]

36. Otoni, C.G.; Avena-Bustillos, R.J.; Olsen, C.W.; Bilbao-Sáinz, C.; McHugh, T.H. Mechanical and water barrier properties of isolated soy protein composite edible films as affected by carvacrol and cinnamaldehyde micro and nanoemulsions. Food Hydrocoll. 2016, 57, 72-79. [CrossRef]

37. Li, K.; Jin, S.; Chen, H.; He, J.; Li, J. A high-performance soy protein isolate-based nanocomposite film modified with microcrystalline cellulose and $\mathrm{cu}$ and zn nanoclusters. Polymers 2017, 9, 167. [CrossRef]

38. Li, K.; Jin, S.; Liu, X.; Chen, H.; He, J.; Li, J. Preparation and characterization of chitosan/soy protein isolate nanocomposite film reinforced by cu nanoclusters. Polymers 2017, 9, 247. [CrossRef]

(C) 2017 by the authors. Licensee MDPI, Basel, Switzerland. This article is an open access article distributed under the terms and conditions of the Creative Commons Attribution (CC BY) license (http:/ / creativecommons.org/licenses/by/4.0/). 